\title{
Tumor Growth Rate as a Prognostic Factor for Metastatic or Recurrent Adenoid Cystic Carcinoma of the Head and Neck Patients Treated with Carboplatin Plus Paclitaxel
}

\section{Naoki Fukuda ( $\square$ naoki.fukuda@jfcr.or.jp )}

The Cancer Institute Hospital of The Japanese Foundation for Cancer Research https://orcid.org/0000-0002-5475-9309

\section{Yu Fujiwara}

The Cancer Institute Hospital of The Japanese Foundation for Cancer Research Xiaofei Wang

The Cancer Institute Hospital of The Japanese Foundation for Cancer Research Akihiro Ohmoto

The Cancer Institute Hospital of The Japanese Foundation for Cancer Research

\section{Tetsuya Urasaki}

The Cancer Institute Hospital of The Japanese Foundation for Cancer Research

\section{Naomi Hayashi}

The Cancer Institute Hospital of The Japanese Foundation for Cancer Research

\section{Yasuyoshi Sato}

The Cancer Institute Hospital of The Japanese Foundation for Cancer Research

\section{Kenji Nakano}

The Cancer Institute Hospital of The Japanese Foundation for Cancer Research

\section{Mayu Yunokawa}

The Cancer Institute Hospital of The Japanese Foundation for Cancer Research

\section{Makiko Ono}

The Cancer Institute Hospital of The Japanese Foundation for Cancer Research Junichi Tomomatsu

The Cancer Institute Hospital of The Japanese Foundation for Cancer Research Shunji Takahashi

The Cancer Institute Hospital of The Japanese Foundation for Cancer Research

\section{Research article}

Keywords: Head and Neck Neoplasms, Carcinoma, Adenoid Cystic, Chemotherapy, Prognostic factor 
Posted Date: May 8th, 2020

DOI: https://doi.org/10.21203/rs.3.rs-26488/v1

License: (9) This work is licensed under a Creative Commons Attribution 4.0 International License. Read Full License

Version of Record: A version of this preprint was published at European Archives of Oto-RhinoLaryngology on November 21st, 2020. See the published version at https://doi.org/10.1007/s00405-02006481-y. 


\section{Abstract}

Background: Large prospective studies of chemotherapy for metastatic or recurrent adenoid cystic carcinoma (ACC) of the head and neck are lacking due to the rarity of ACC. The aim of this study is to evaluate the efficacy of carboplatin plus paclitaxel toward ACC and perform an exploratory investigation of the prognostic factors to investigate the optimal strategy for metastatic or recurrent ACC.

Methods: We retrospectively analyzed recurrent or metastatic ACC patients treated with carboplatin plus paclitaxel between April 2007 and September 2019 in our hospital. Objective response rate (ORR), disease control rate (DCR), progression-free survival (PFS) and overall survival (OS) were evaluated, and an exploratory analysis of the prognostic factors including tumor growth rate (TGR) was conducted.

Results: A total of 26 ACC patients were enrolled. ORR and DCR were $11.5 \%$ and $76.9 \%$; the median PFS and OS were 8.1 and 22.3 months, respectively. From the results of the multivariate analysis, higher ( $\geq$ $6 \%$ /month) TGR was associated with worse PFS (hazard ratio [HR] 7.00, 95\% $\mathrm{Cl} 1.34-36.53, \mathrm{p}=0.02$ ) and OS (HR 29.33, 95\% Cl 3.38-254.80, p<0.01). The median PFS (10.6 vs. 6.6 months, log-rank $p<0.05)$ and OS (48.5 vs. 16.9 months, log-rank $p<0.01)$ were significantly shorter in patients with higher TGR.

Conclusions: Carboplatin plus paclitaxel showed modest efficacy for recurrent or metastatic ACC patients. Watchful waiting may be optimal for ACC patients with lower TGR. Systemic chemotherapy should be considered when TGR increases during active surveillance.

\section{Introduction}

Adenoid cystic carcinoma (ACC) is a rare form of head and neck cancer. The yearly incidence of ACC is reported to be 3 to 4.5 cases per million, which represents approximately $1 \%$ of all head and neck cancers $[1,2]$. It mainly originates from major and minor salivary glands, accounting for about $10 \%$ of all salivary gland tumors [3]. The prognosis of ACC is reported to be indolent, with 5 - and 10-year overall survival (OS) rate of $90.3 \%$ and $79.9 \%$, respectively [4]. However, it is difficult to cure ACC, with a recurrence rate of up to 100\% 30-years after curative treatment [5]. Therefore, most ACC patients require salvage therapy, including chemotherapy, at some point in their clinical courses.

The evidence for the efficacy of salvage chemotherapy in recurrent or metastatic ACC patients is not well established. Several reports describe modest efficacy of carboplatin plus paclitaxel in patients with salivary gland carcinoma (SGC), including patients with ACC and non-ACC histology [6-8]. Moreover, carboplatin plus paclitaxel has frequently been used as a therapeutic option for recurrent or metastatic ACC patients in real-world clinical practice, as it can be conveniently administered in an outpatient setting. However, due to the rarity of ACC, the number of patients included in previous studies is small. The optimal timing to initiate systemic chemotherapy for metastatic or recurrent ACC is controversial, as ACC is a slow-growing and chemotherapy-resistant tumor. Some reports suggested that watchful waiting might be the appropriate strategy for asymptomatic and indolent SGC [9]. We therefore analyzed clinical outcomes of ACC patients treated with carboplatin plus paclitaxel in an effort to assess treatment 
efficacy, and performed an exploratory analysis on prognostic factors of carboplatin plus paclitaxel in the treatment of ACC to investigate the optimal timing to initiate chemotherapy.

\section{Patients And Methods}

We performed a retrospective analysis of patients with recurrent or metastatic ACC who were treated with carboplatin plus paclitaxel from April 2007 to September 2019 at the Department of Medical Oncology of the Cancer Institute Hospital of the Japanese Foundation for Cancer Research. All patients were administered a treatment consisting of carboplatin (area under the curve [AUC] $=6$ ) and paclitaxel $\left(200 \mathrm{mg} / \mathrm{m}^{2}\right.$ ) once every 3 weeks. Premedication with an $\mathrm{H}_{1}$ and $\mathrm{H}_{2}$ histamine antagonist plus dexamethasone was intravenously administered before each infusion. Intravenous administration of a serotonin-3 $\left(5-\mathrm{HT}_{3}\right)$ antagonist was provided for antiemetic prophylaxis. Dose modifications or delays during the treatment schedules were allowed according to the physicians' discretion.

Treatment responses were evaluated by computed tomography (CT) scans according to the Response Evaluation Criteria in Solid Tumors (RECIST) criteria (ver. 1.1). Progression-free survival (PFS) was defined as the time between treatment initiation and disease progression or death by any cause. We defined overall survival (OS) as the time between treatment initiation and death by any cause. Tumor growth rate (TGR) was defined as the percentage change in tumor volume over 1 month (\%/month). TGR was calculated by TGR $=100 \times(\exp (T G)-1)$, where $T G=3 \times \log (\mathrm{D} 2 / \mathrm{D} 1) /$ time (months) $[10,11]$. Tumor size (D) was determined using the sum of longest diameters of target lesions according to RECIST v1.1. Non-target and new lesions were excluded. D1 represents tumor sizes at the penultimate CT evaluation date (date 1), and D2 represents the CT evaluation date (date 2) immediately prior to starting carboplatin plus paclitaxel. Time (months) is defined as (date 2 - date $1+1) \times 365 / 12$.

We used EZR ( $R$ ver. 2.13.0) software to perform the statistical analyses [12]. PFS and OS were estimated by the Kaplan-Meier method and were compared using a log-rank test. The survival results are expressed as the median value with a $95 \%$ confidence interval $(\mathrm{Cl})$. The Cox hazard regression model was used to analyze the prognostic factors. A stepwise Cox proportional hazards model was used to evaluate independent prognostic factors for each variable that was significant in the univariate analysis. We selected final covariates using a backward stepdown selection process with the Akaike information criterion. The association between TGR and survival time was analyzed using Spearman's rank correlation coefficient. Statistical significance was defined as $p<0.05$.

\section{Results}

\section{Patients and treatment delivery}

Between April 2007 and September 2019, 26 ACC patients were treated with carboplatin plus paclitaxel at our hospital. Patient characteristics are shown in Table 1. The median age was 54 years (range $30-74$ ), and 15 (58\%) patients were female. The median body mass index (BMI) was 20.8 (range 14.1-27.7) 
$\mathrm{kg} / \mathrm{m}^{2}$. The most common primary tumor site was the submandibular gland (34.6\%), followed by the oral cavity $(19.2 \%)$, and the parotid gland $(15.3 \%)$. Approximately $58 \%$ of the patients had received surgery, and $69 \%$ had received radiotherapy for the primary tumor. The metastatic sites were lung ( $85 \%)$, bone (23\%), lymph nodes (15\%) and liver (15\%). Twenty (77\%) patients had measurable target lesions, and the median tumor size of the maximum target lesion was $20.7 \mathrm{~mm}$ (range 11.0-80.1). MYB-NFIB in situ hybridization (ISH) became available in our hospital after 2015, and 5 patients underwent testing. MYBNFIB gene fusion was detected in all of the patients evaluated. The TGR before starting chemotherapy was $5.7 \%$ /month (range $0.7-46.4$ ) for the 21 evaluable patients. The median time from the diagnosis of recurrence or metastasis to the initiation of chemotherapy was 8.0 months (range $0.2-46.0$ ). 
Table 1

Patient characteristics $(\mathrm{N}=26)$.

\begin{tabular}{|c|c|c|c|}
\hline & & Number & $\%$ \\
\hline Age (years) & Median (range) & $55(30-74)$ & \\
\hline \multirow[t]{2}{*}{ Sex } & Male & 11 & 42.3 \\
\hline & Female & 15 & 57.7 \\
\hline BMI $\left(\mathrm{kg} / \mathrm{m}^{2}\right)$ & Median (range) & $20.8(14.1-27.7)$ & \\
\hline \multirow[t]{2}{*}{ ECOG PS } & 0 & 13 & 50.0 \\
\hline & $\geq 1$ & 12 & 50.0 \\
\hline \multirow[t]{6}{*}{ Primary site } & Submandibular & 9 & 34.6 \\
\hline & Oral cavity & 5 & 19.2 \\
\hline & Parotid & 4 & 15.4 \\
\hline & Lacrimal gland & 2 & 7.7 \\
\hline & Orbital cavity & 2 & 7.7 \\
\hline & Others & 4 & 15.4 \\
\hline \multirow[t]{4}{*}{ Metastatic sites } & Lung & 22 & 84.6 \\
\hline & Bone & 6 & 23.0 \\
\hline & Lymph node & 4 & 15.3 \\
\hline & Liver & 4 & 15.3 \\
\hline \multirow[t]{3}{*}{ Prior therapies } & Surgery & 15 & 57.7 \\
\hline & Radiation & 18 & 69.2 \\
\hline & Chemotherapy & 6 & 23.1 \\
\hline Maximum tumor size (mm) & Median (range) & $20.7(11.0-80.1)$ & \\
\hline
\end{tabular}

The data cutoff was March 23, 2020, and the median follow-up time was 17.6 months (range; $1.8-$ 121.5). PFS and OS events were observed in 20 (77\%) and 17 (65\%) of the patients, respectively. The median treatment cycles of carboplatin plus paclitaxel were 6 (range; 1-24). Subsequent chemotherapy including immunotherapy after failure of carboplatin plus paclitaxel was performed in 12 (46\%) patients.

\section{Efficacy of carboplatin plus paclitaxel}


The median PFS for all patients receiving carboplatin plus paclitaxel was 9.2 months ( $95 \% \mathrm{Cl} 5.7-11.0)$ and the median OS was 22.3 months $(95 \% \mathrm{Cl} 16.8-48.5)$ (Fig. 1). The 2-year PFS and OS rates were $13.5 \%(95 \% \mathrm{Cl} 2.4-33.8 \%)$ and $46.4 \%(95 \% \mathrm{Cl} 25.2-65.2)$, respectively. The objective response rate (ORR) and disease control rate (DCR) were $11.5 \%(95 \% \mathrm{Cl} 2.4-30.2)$ and $76.9 \%(95 \% \mathrm{Cl} 56.4-91.0)$, respectively.

\section{Exploratory analysis of prognostic factors}

We evaluated the prognostic factors in patients treated with carboplatin plus paclitaxel. The results of univariate analysis of PFS and OS are shown in Table 2, and those of multivariate analysis are shown in Table 3. Higher tumor growth rate ( $\geq 6 \%$ /month) was an independent prognostic factor for both PFS (hazard ratio [HR] 7.00, 95\% Cl 1.34-36.53, p = 0.02) and OS (HR 29.33, 95\% Cl 3.38-254.80, p < 0.01). Poor Eastern Cooperative Oncology Group (ECOG) performance status (PS) $(\geq 1)$ was also an independent prognostic factor for PFS (HR 5.79, 95\% Cl 1.37-24.5, p = 0.02) and OS (HR 4.69, 95\% Cl $1.03-21.45, p<0.05)$. Kaplan-Meier curves for PFS and OS according to TGR $(<6 \%$ vs. $\geq 6 \% /$ month $)$ are shown in Fig. 2. The median PFS (10.6 vs. 6.6 months, log-rank $p<0.05)$ and OS (48.5 vs. 16.9 months, log-rank $p<0.01$ ) were significantly shorter in higher TGR patients. Spearman rank correlation coefficient also showed negative correlations between TGR and PFS $\left(r_{\mathrm{s}}=-0.64, \mathrm{p}<0.01\right)$ or OS $\left(r_{\mathrm{s}}=-0.55, \mathrm{p}<0.03\right)$ (Fig. 3). 
Table 2

Univariate analysis of progression-free survival (PFS) and overall survival (OS).

\begin{tabular}{|c|c|c|c|c|c|c|}
\hline & \multicolumn{3}{|l|}{ PFS } & \multicolumn{3}{|l|}{ os } \\
\hline & $\mathrm{HR}$ & $95 \% \mathrm{Cl}$ & P-value & $\mathrm{HR}$ & $95 \% \mathrm{Cl}$ & P-value \\
\hline \multicolumn{7}{|l|}{ Age } \\
\hline$\geq 60$ vs. $<60$ & 0.85 & $0.34-2.14$ & 0.73 & 0.57 & $0.21-1.52$ & 0.26 \\
\hline \multicolumn{7}{|l|}{ Sex } \\
\hline Male vs. Female & 0.76 & $0.30-1.92$ & 0.56 & 0.64 & $0.24-1.69$ & 0.37 \\
\hline \multicolumn{7}{|l|}{ BMI } \\
\hline$<18$ vs. $\geq 18$ & 4.49 & $1.44-14.0$ & $<0.01$ & 2.28 & $0.69-7.45$ & 0.17 \\
\hline \multicolumn{7}{|l|}{ ECOG PS } \\
\hline$\geq 1$ vs. 0 & 2.93 & $1.07-7.98$ & 0.04 & 2.39 & $0.81-7.00$ & 0.11 \\
\hline \multicolumn{7}{|l|}{ Primary site } \\
\hline Major salivary gland vs. others & 1.15 & $0.46-2.86$ & 0.77 & 1.19 & $0.46-3.10$ & 0.72 \\
\hline \multicolumn{7}{|l|}{ Extra-pulmonary disease } \\
\hline Yes vs. no & 1.44 & $0.58-5.78$ & 0.43 & 1.37 & $0.52-3.57$ & 0.52 \\
\hline \multicolumn{7}{|l|}{ Maximum tumor size } \\
\hline$\geq 20$ vs. $<20 \mathrm{~mm}$ & 2.17 & $0.74-6.31$ & 0.16 & 1.66 & $0.53-5.17$ & 0.38 \\
\hline \multicolumn{7}{|l|}{ TGR } \\
\hline$\geq 6$ vs. $<6 \% /$ month & 3.45 & $1.02-11.72$ & $<0.05$ & 6.91 & $1.76-27.2$ & $<0.01$ \\
\hline
\end{tabular}


Table 3

Multivariate analysis of progression-free survival (PFS) and overall survival (OS).

PFS

$\mathrm{HR} \quad 95 \% \mathrm{Cl}$

19.9

$2.43-$

163.50

OS

P-value HR

$95 \% \mathrm{Cl}$

P-value

BMI

$<18$ vs. $\geq 18$

5.79

$1.37-24.5$

0.02

4.69

$1.03-21.45$

0.046

Primary site

Major salivary gland vs. others

4.58

$0.94-22.30$

0.06

5.10

$0.97-26.71$

0.54

TGR

$\geq 6$ vs. $<6 \% /$ month

7.00

$1.34-36.53$

0.02

29.33

$3.38-254.80$

$<0.01$

Abbreviations; PFS: Progression-free survival, OS: Overall survival, HR: Hazard ratio, Cl: confidence interval, ECOG PS: Eastern Cooperative Oncology Group performance status, BMI: Body Mass Index, TGR: Tumor growth rate

\section{Discussion}

A standard chemotherapeutic regimen for recurrent or metastatic ACC has not been previously established. This retrospective analysis evaluated the efficacy of carboplatin plus paclitaxel in a larger number of ACC patients than in previously reports. Moreover, this is the first report to evaluate the prognostic factors for PFS and OS in ACC patients treated with carboplatin plus paclitaxel.

The results of our study indicate a modest efficacy of carboplatin plus paclitaxel for recurrent or metastatic ACC patients. There are a limited number of prospective studies investigating the effects of chemotherapy for ACC. A small prospective trial involving a regimen of cyclophosphamide, doxorubicin, and cisplatin (CAP) on 22 SGC patients, including 12 ACC patients, demonstrated a 25\% ORR for the ACC patients $[13,14]$. However, this triplet regimen is difficult to administer in an outpatient setting, due to the amount of hydration required for cisplatin administration. Recently, several single-arm prospective phase 2 trials of multi-kinase inhibitors (MKIs), such as sunitinib, sorafenib, axitinib, dasatinib, and lenvatinib, for recurrent or metastatic ACC patients have been conducted [15-20]. In these trials, the number of patients enrolled were 14-40, the ORR were $0-15 \%$, and the median PFS were 4.8-17.5 months. To date, these MKIs are not approved internationally for use in ACC patients. Pembrolizumab, a monoclonal antibody targeting programmed cell death 1 (PD-1), has been approved for metastatic or recurrent programmed cell death ligand 1 (PD-L1) positive cancers, regardless of their primary sites. However, PDL1 positivity in ACC is reported to be low [21]. In a phase $1 \mathrm{~b}$ trial of pembrolizumab for various PD-L1 
positive solid tumors, an objective response was not observed in ACC patients (0/2), even when PD-L1 positive [22]. In several prospective phase 2 trials, the ORR was $8.6 \%(4 / 46)$ in nivolumab alone, and $6 \%$ $(2 / 32)$ in nivolumab plus ipilimumab, suggesting the limited efficacy of immune checkpoint inhibitors for ACC $[23,24]$. Despite being retrospective data, the ORR, PFS and OS of carboplatin plus paclitaxel in our cohort were comparable with the results of these clinical trials. Moreover, a carboplatin-based regimen can be administrated in an outpatient setting because it does not require extensive hydration, and is less expensive than MKIs and immunotherapies. Considering its convenience and cost-effectiveness, carboplatin plus paclitaxel represents a viable therapeutic option for recurrent or metastatic ACC patients.

A large multicenter prospective study $(\mathrm{N}=470)$ for ACC suggested that age, $\mathrm{BMI}$, and lymph node invasion were significant prognostic factors for ACC [25]. Our exploratory analysis of prognostic factors indicated a link between higher TGR or poor ECOG PS and worse PFS and OS. BMI was also a prognostic factor for PFS in our results, which was consistent with the previous study. In the previous cohort, only $18 \%$ of the patients underwent chemotherapy and the detailed therapeutic data were excluded from the search for prognostic factors. Therefore, our results can be meaningful as all patients included in the cohort received chemotherapy with the same therapeutic regimen.

The ORR and DCR of our cohort were $11.5 \%$ and $76.9 \%$, suggesting that the aim of a carboplatin plus paclitaxel regimen should be disease control, not tumor shrinkage. Patients with lower TGR demonstrated longer OS (median OS; 48.5 months). Therefore, watchful waiting and active surveillance can be an optimal strategy for patients with slow-growing (lower TGR) ACC. Initiation of systemic chemotherapy should be considered when TGR increases up to $6 \% /$ month during active surveillance or the patient develops tumor-related symptoms affecting ECOG PS. Patients with massive tumor volumes, aggressive TGR or severe tumor related symptoms might not benefit from carboplatin plus paclitaxel. For these patients, palliative care would be preferable to intensive systemic chemotherapy, which accounts for the patients' quality of life.

Our study has several limitations. First, this was a retrospective analysis of a small number of patients at a single institute. Due to the rarity of ACC, not more than 46 ACC patients were enrolled in previous prospective studies investigating chemotherapy. Our results should be interpreted in the context of the difficulty of conducting large randomized phase 3 trials for ACC. Second, although the pathological specimens were diagnosed by a pathologist who specializes in head and neck cancers, genetic confirmation with MYB fusion genetic testing could not be performed in the majority of the patients. Third, some patients were excluded by the TGR assessments due to the absence of measurable target lesions. This may cause selection bias. Though we used a cutoff of $6 \% /$ month for TGR according to the median value of enrolled patients, the optimal cutoff value was not established. To resolve these limitations, we are now planning a prospective multicenter cohort study.

\section{Conclusions}


Carboplatin plus paclitaxel showed modest efficacy in patients with metastatic or recurrent head and neck ACC. This treatment regimen represents a valid therapeutic option for selected ACC patients in an outpatient setting. TGR and ECOG PS were independent prognostic factors for PFS and OS. During watchful waiting and active surveillance, when TGR increase up to $6 \% /$ month, initiation of chemotherapy should be considered. A prospective multicenter cohort study with a greater number of patients is required to establish firm evidence supporting this treatment regimen for this rare cancer.

\section{Abbreviations}

ACC: adenoid cystic carcinoma; ORR: Objective response rate; DCR: disease control rate; PFS: progression-free survival; OS: overall survival; TGR: tumor growth rate; HR: hazard ratio; SGC: salivary gland carcinoma; AUC: area under the curve; $5-\mathrm{HT}_{3}$ : serotonin-3; $\mathrm{CT}$ : computed tomography; RECIST:

Response Evaluation Criteria in Solid Tumors; TGR: Tumor growth rate; BMI: body mass index; ISH: in situ hybridization; ECOG: Poor Eastern Cooperative Oncology Group; PS: performance status; MKI: multikinase inhibitor; PD-1: programmed cell death 1; PD-L1: programmed cell death ligand 1

\section{Declarations}

\section{Ethics approval and consent to participate}

This study was approved by the institutional review board of the Cancer Institute Hospital of the Japanese Foundation for Cancer Research (No. 2019-1219). This study was conducted in accordance with the Helsinki Declaration of 1964 and later versions. Given the retrospective nature of this study, the requirement for informed consent from the patients was waived by our hospital's institutional review board.

\section{Consent for publication}

Not applicable. This is just the same as described above.

\section{Competing interests}

The authors declare that they have no competing interests related to this work.

\section{Availability of data and materials}

The datasets used and/or analyzed during the current study are available from the corresponding author on reasonable request. 


\section{Funding}

This research was not supported by a specific grant from funding agencies in the public, commercial, or not-for-profit sectors.

\section{Authors' contributions}

NF wrote the manuscript; YF, XW, AO, TU, NH, YS, KN, MY, MO, JT, and ST contributed critical revisions to the manuscript.

\section{Acknowledgments}

We thank all members of the Department of Head and Neck Oncology at the Cancer Institute Hospital of the Japanese Foundation for Cancer Research for patient referral. We also thank the members of the Department of Pathology at the Cancer Institute Hospital of the Japanese Foundation for Cancer Research for their assistance in patient diagnosis.

\section{References}

1. Bjørndal K, Krogdahl A, Therkildsen MH, Overgaard J, Johansen J, Kristensen CA, et al. Salivary gland carcinoma in Denmark 1990-2005: a national study of incidence, site and histology. Results of the Danish Head and Neck Cancer Group (DAHANCA). Oral Oncol. 2011;47:677-82.

2. Dodd RL, Slevin NJ. Salivary gland adenoid cystic carcinoma: a review of chemotherapy and molecular therapies. Oral Oncol. 2006;42:759-69.

3. Bradley PJ. Adenoid cystic carcinoma of the head and neck: a review. Curr Opin Otolaryngol Head Neck Surg. 2004;12:127-32.

4. Ellington $\mathrm{CL}$, Goodman M, Kono SA, Grist W, Wadsworth $\mathrm{T}$, Chen AY, et al. Adenoid cystic carcinoma of the head and neck: Incidence and survival trends based on 1973-2007 Surveillance, Epidemiology, and End Results data. Cancer. 2012;118:4444-51.

5. Jones AS, Hamilton JW, Rowley H, Husband D, Helliwell TR. Adenoid cystic carcinoma of the head and neck. Clin Otolaryngol Allied Sci. 1997;22:434-43.

6. Airoldi M, Fornari G, Pedani F, Marchionatti S, Gabriele P, Succo G, Bumma C. Paclitaxel and carboplatin for recurrent salivary gland malignancies. Anticancer Res. 2000;20:3781-3.

7. Ruzich JC, Ciesla MC, Clark JI. Response to paclitaxel and carboplatin in metastatic salivary gland cancer: a case report. Head Neck. 2002;24:406-10.

8. Nakano K, Sato Y, Sasaki T, Shimbashi W, Fukushima H, Yonekawa H, et al. Combination chemotherapy of carboplatin and paclitaxel for advanced/metastatic salivary gland carcinoma 
patients: differences in responses by different pathological diagnoses. Acta Otolaryngol. 2016;136:948-51.

9. Lagha A, Chraiet N, Ayadi M, Krimi S, Allani B, Rifi H, et al. Systemic therapy in the management of metastatic or advanced salivary gland cancers. Head Neck Oncol. 2012;4:19.

10. Ferté C, Fernandez M, Hollebecque A, Koscielny S, Levy A, Massard C, et al. Tumor growth rate is an early indicator of antitumor drug activity in phase I clinical trials. Clin Cancer Res. 2014;20:246-252.

11. Ferté C, Koscielny S, Albiges L, Rocher L, Soria JC, lacovelli R, et al. Tumor growth rate provides useful information to evaluate sorafenib and everolimus treatment in metastatic renal cell carcinoma patients: an integrated analysis of the TARGET and RECORD phase 3 trial data. Eur Urol. 2014;65:713-720.

12. Kanda Y. Investigation of the freely-available easy-to-use software "EZR" (Easy R) for medical statistics. Bone Marrow Transplant. 2013;48:452-458.

13. Greagan ET, Woods JE, Rubin J, Schaid DJ. Cisplatin-based chemotherapy for neoplasms arising from salivary glands and contiguous structures in the head and neck. Cancer. 1988;62:2313-9.

14. Licitra L, Cavina R, Grandi C, Palma SD, Guzzo M, Demicheli R, et al. Cisplatin, doxorubicin and cyclophosphamide in advanced salivary gland carcinoma. A phase II trial of 22 patients. Ann Oncol. 1996;7:640-2.

15. Chau NG, Hotte SJ, Chen EX, Chin SF, Turner S, Wang L, et al. A phase II study of sunitinib in recurrent and/or metastatic adenoid cystic carcinoma (ACC) of the salivary glands: Current progress and challenges in evaluating molecularly targeted agents in ACC. Ann Oncol. 2012;23:1562-1570.

16. Thomson DJ, Silva P, Denton K, Bonington S, Mak SK, Swindell R, et al. Phase II trial of sorafenib in advanced salivary adenoid cystic carcinoma of the head and neck. Head Neck. 2015;37:182-187.

17. Locati LD, Perrone F, Cortelazzi B, Bergamini C, Bossi P, Civelli E, et al. A phase Il study of sorafenib in recurrent and/or metastatic salivary gland carcinomas: Translational analyses and clinical impact. Eur J Cancer. 2016;69:158-165.

18. Ho AL, Dunn L, Sherman EJ, Fury MG, Baxi SS, Chandramohan R, et al. A phase II study of axitinib (AG-013736) in patients with incurable adenoid cystic carcinoma. Ann Oncol. 2016;27:1902-1908.

19. Wong SJ, Karrison T, Hayes DN, Kies MS, Cullen KJ, Tanvetyanon T, et al. Phase II trial of dasatinib for recurrent ormetastatic c-KIT expressing adenoid cystic carcinoma and for nonadenoid cystic malignant salivary tumors. Ann Oncol. 2016;27:318-323.

20. Tchekmedyian V, Sherman EJ, Dunn L, Tran C, Baxi S, Katabi N, et al. Phase II Study of Lenvatinib in Patients With Progressive, Recurrent or Metastatic Adenoid Cystic Carcinoma. J Clin Oncol. 2019;37:1529-1537.

21. Vital D, Ikenberg K, Moch H, Rössle M, Huber GF. The expression of PD-L1 in salivary gland carcinomas. Sci Rep. 2019;9:12724.

22. Cohen RB, Delord JP, Doi T, Piha-Paul SA, Liu SV, Gilbert J, et al. Pembrolizumab for the Treatment of Advanced Salivary Gland Carcinoma: Findings of the Phase 1b KEYNOTE-028 Study. Am J Clin Oncol. 2018;41:1083-88. 
23. Fayette J, Even C, Digue L, Geoffrois L, Rolland F, Cupissol D, et al. NISCAHN: A phase II, multicenter nonrandomized trial aiming at evaluating nivolumab $(\mathrm{N})$ in two cohorts of patients (pts) with recurrent/metastatic (R/M) salivary gland carcinoma of the head and neck (SGCHN), on behalf of the Unicancer Head \& Neck Group. J Clin Oncol. 2019;37 15 suppl:6083.

24. Tchekmedyian V, Sherman EJ, Dunn L, Fetten JV, Michel LS, Kriplani A, et al. A phase II trial cohort of nivolumab plus ipilimumab in patients (Pts) with recurrent/metastatic adenoid cystic carcinoma (R/M ACC). J Clin Oncol. 2019;37 15 suppl:6084.

25. Atallah S, Casiraghi O, Fakhry N, Wassef M, Uro-Coste E, Espitalier F, et al. A prospective multicentre REFCOR study of 470 cases of head and neck Adenoid cystic carcinoma: epidemiology and prognostic factors. Eur J Cancer. 2020;130:241-249.

\section{Figures}

(a)

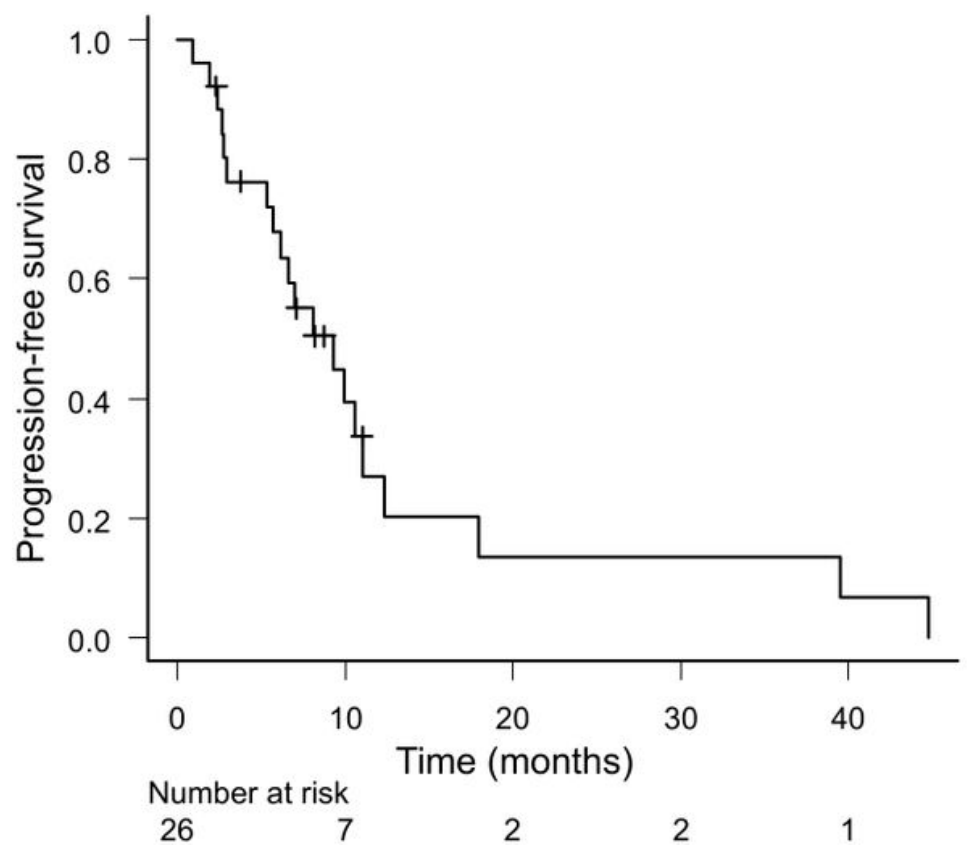

(b)

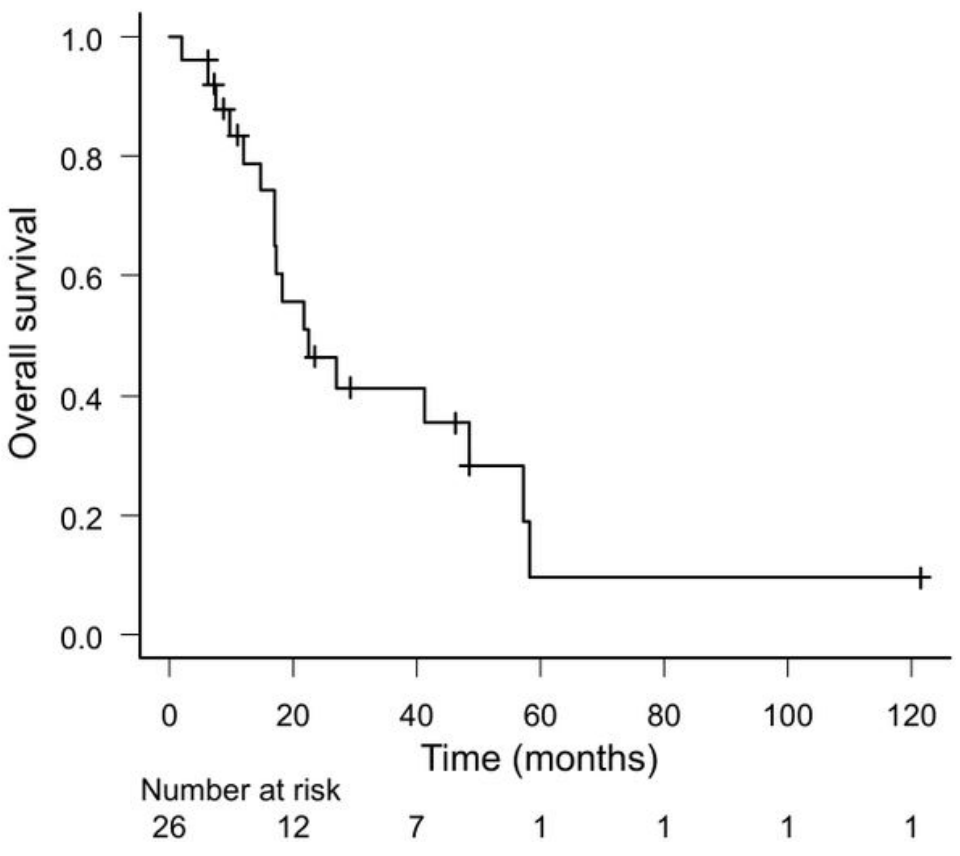

Figure 1

a Kaplan-Meier curves of progression-free survival (PFS). b Kaplan-Meier curves of overall survival (OS). 
(a)

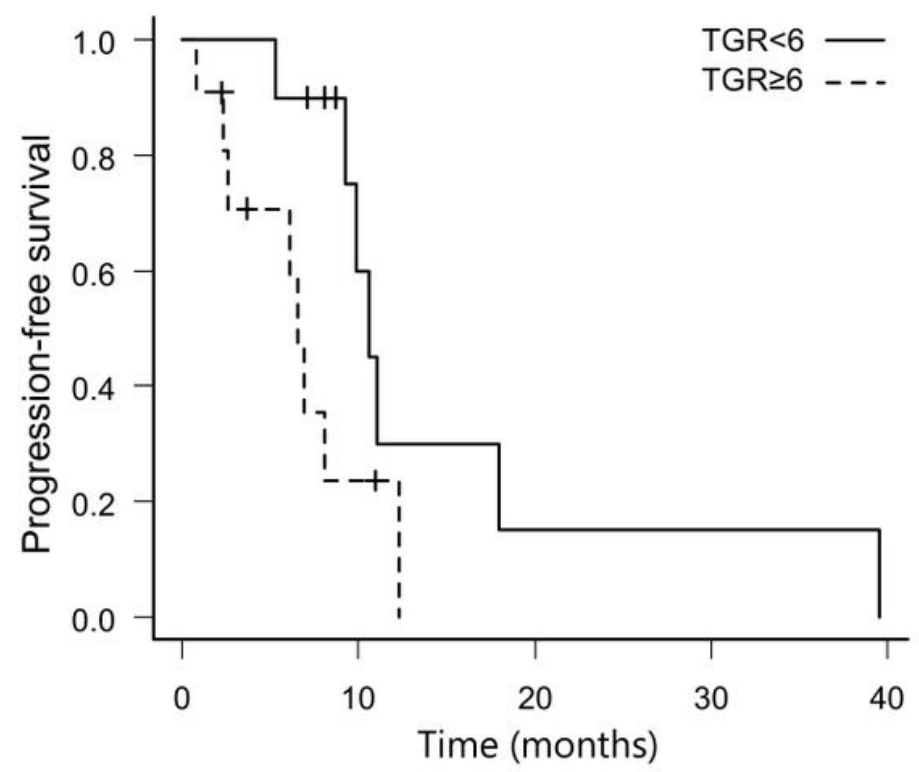

Number at risk

TGR<6 10

TGR $\geq 6 \quad 11$
4
2 (b)

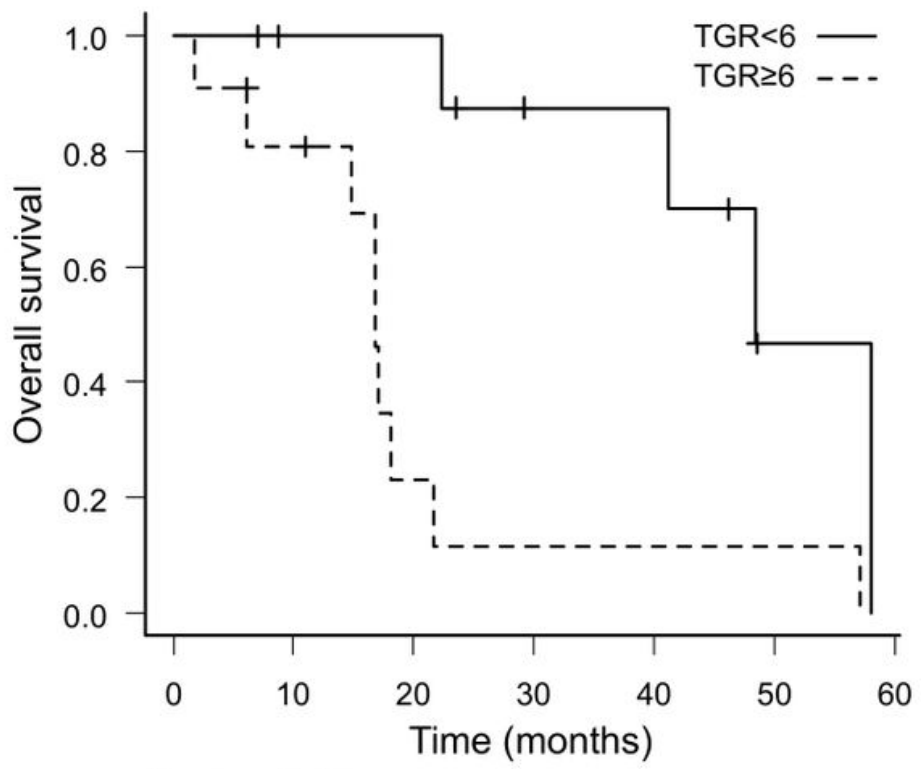

Number at risk

$\begin{array}{llllllll}\text { TGR }<6 & 10 & 8 & 8 & 5 & 5 & 1 & 0 \\ \text { TGR } \geq 6 & 11 & 8 & 2 & 1 & 1 & 1 & 0\end{array}$

\section{Figure 2}

a Progression-free survival (PFS) according to tumor growth rate (TGR). b Overall survival (OS) according to tumor growth rate (TGR).

(a)

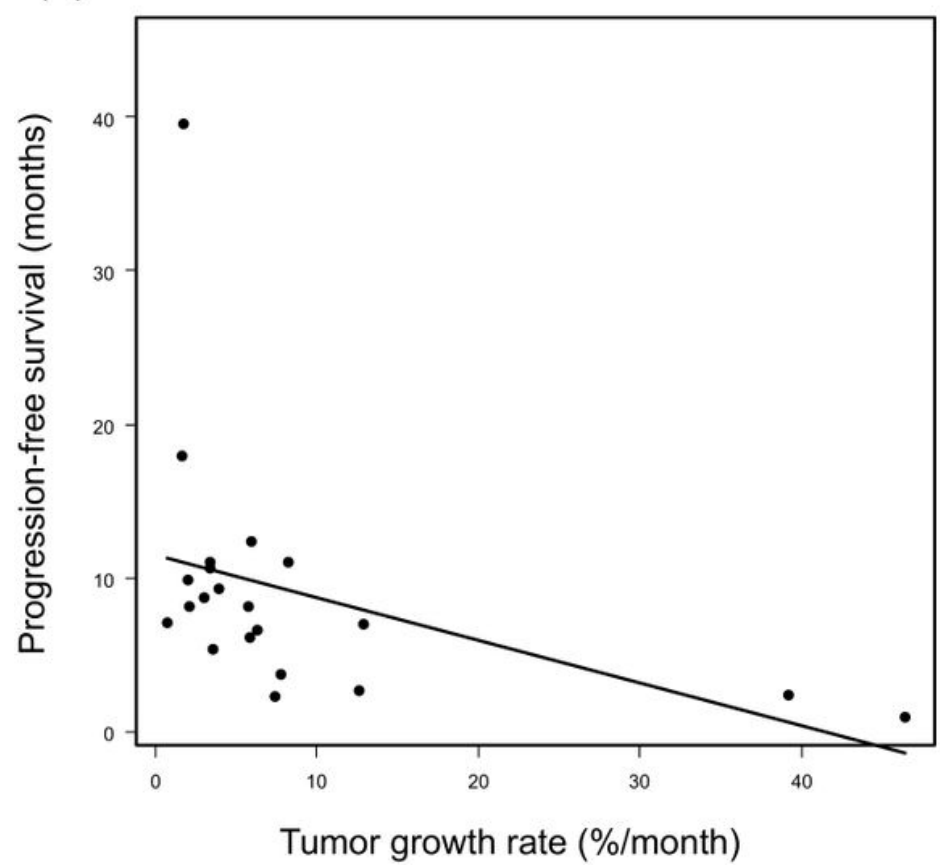

(b)

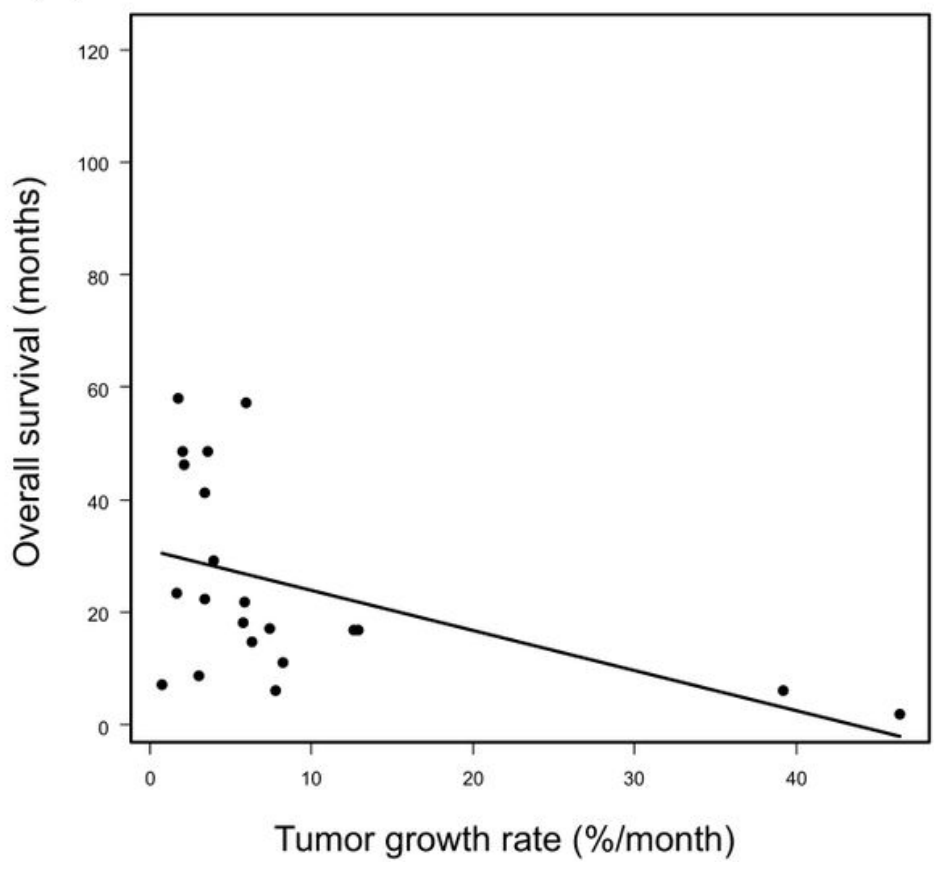

Figure 3

Association between tumor growth rate (TGR) and survival outcomes evaluated with Spearman's rank correlation coefficient: a Progression-free survival, b Overall survival. 